\title{
Carrot Yield and Shape Altered by Seeding Rate and Raised Beds in Clay-loam Soil
}

\author{
Charlie L. Rohwer \\ University of Minnesota Southern Research and Outreach Center, \\ Waseca, MN 56093
}

Additional index words. cylindricity, Daucus carota, effects size, flat bed, plant population

\begin{abstract}
Carrots (Daucus carota L. var sativus) in the midwestern United States are generally raised commercially on sandy-loam or muck soils. Some smaller growers may not have the luxury of an ideal soil type, so raised beds are often recommended to improve taproot growth. To determine specific yield and shape responses of carrots to raised-bed culture in heavy soil, three hybrids ('Cupar', 'Envy', and 'Naval') were grown in 2019 and 2020 on raised or flat beds in clay-loam soil. In addition, two seeding rates (high or low) were incorporated into the split-split plot design. 'Cupar' was larger and less misshapen than the other hybrids, but total marketable yields were similar among all three. 'Naval' was the most cylindrical. High seeding rate generally resulted in more numerous but smaller marketable roots and no change in total marketable weight. Raised beds caused a $10.6 \%$ increase in total marketable weight by allowing more marketable roots classified as "short" (between 76 and $127 \mathrm{~mm}$ long, diameter $>25 \mathrm{~mm}$ ) to grow to lengths more than $127 \mathrm{~mm}$ long. The average taproot cylindricity was increased and diameter decreased by growing on raised beds. Soil penetration resistance at $7.6 \mathrm{~cm}$ was correlated with many of the measured responses.
\end{abstract}

Carrots are an economically important crop in the upper midwestern United States, with 3493 ha harvested in Minnesota, Michigan, and Wisconsin in $2017 ; 84 \%$ of the acreage was for processing [U.S. Department of Agriculture (USDA) National Agricultural Statistics Service (NASS), 2020]. Soil compaction generally negatively impacts taproot length and yield (Johansen et al., 2015; Pietola, 1995). Typically, carrots are grown on peat/muck or sandy-loam soils that are deeply cultivated to reduce compaction for encouraging straight, uniform taproots. University extension publications and popular press often advise growers and gardeners to plant carrots on raised beds for similar reasons (Delahaut and Newenhouse, 2011; Jauron and Wallace, 2017; Kelley and Phatak, 2009; Smetanka, 2017; Thompson, 2017). Especially on fine-textured mineral soils (not sandy or peat/ muck), it is reasonable to assume that raised

Received for publication 7 Mar. 2021. Accepted for publication 12 Apr. 2021.

Published online 27 May 2021.

I thank Scott Coy for assistance with field work and carrot data collection; Bejo Seeds and Seminis Vegetable Seeds for donating seeds, and Vince Fritz, Benjamin Phillips; and three anonymous reviewers for manuscript input.

This research is supported by the Minnesota Agricultural Experiment Station and the University of Minnesota Southern Research and Outreach Center.

C.L.R. is the corresponding author. E-mail: rohw0009@umn.edu.

This is an open access article distributed under the CC BY-NC-ND license (https://creativecommons. org/licenses/by-nc-nd/4.0/). beds reduce compaction and soil density where the taproot grows. In addition, raised beds can improve water relations in the root zone, especially in wet soils (Bakker et al., 2005). Water relations early in a carrot crop cycle may influence length potential and straightness of the harvested taproot, especially in heavy soils (Brown and Gracie, 2000). A carrot taproot's ability to avoid areas of low water availability suggests that after germination, drier surface soil in raised beds may encourage longer taproots. However, data to illustrate the specific effects of raised beds on carrots are lacking.

Weed control in carrots can be especially challenging, because carrot seeds are slow to germinate and a canopy is slow to develop. One strategy to reduce weed pressure is to seed at a higher rate, reducing the time to develop a canopy for shading weed seedlings (Colquhoun et al., 2020). However, increased population causes shorter taproots (Thompson, 1969).

Carrot varieties can be classified by their general shape and use characteristics. For example, Chantenay carrots are generally wide and conical-shaped, with medium-length, and are often recommended over other types for heavy or compacted soils. Imperator carrots are long, and generally perform best on sandy-loam or peat/muck soils, although breeders can recommend specific varieties that may perform well on mineral soils. Nantes-type are highly cylindrical and medium-length. Each type has utility in fresh-market or processing industries.

In this study, three carrot hybrids were grown (Chantenay-type, Imperator-type, and Nantes-type) to determine the effects of raised beds and elevated seeding rates, and the interaction between them, on carrot taproot size, shape, and yield in a clay-loam soil.

\section{Materials and Methods}

The experiment was planted as a splitsplit-plot design in 2019 and 2020 at the University of Minnesota Southern Research and Outreach Center in Waseca, MN (lat. $44.08^{\circ} \mathrm{N}$, long. $93.52^{\circ} \mathrm{W}$ ). The main plot was carrot hybrid ( $\mathrm{n}=3$; Chantenay-type 'Cupar' or Nantes-type 'Naval' from Bejo Seeds, Oceano, CA; Imperator-type 'Envy' from Seminis Seeds, St. Louis, MO), the first split plot was seeding rate $(n=2$, described in the following) and the split-split plot was bed shape $(\mathrm{n}=2$; flat or raised bed). There were six replicated complete blocks per year.

The soil was a Nicollet clay loam, a fine-textured, mesic Aquic Hapludoll. Soil test properties are described in Table 1 . The previous crop was spring wheat with fall fallow. On 29 Apr. 2019 or 22 Apr. 2020, the field was fertilized with phosphorus (triple superphosphate, $0 \mathrm{~N}-20.1 \mathrm{P}-0 \mathrm{~K}$ ), potassium (KCl, 0N-0P-49.8K), sulfur (gypsum, $18 \% \mathrm{~S}$ ), and boron (Granubor; US Borax, Boron, CA; 15\% B) as described in Table 1, and cultivated with a rototiller. Raised beds 7.6 to $10.2 \mathrm{~cm}$ tall and $36.6 \mathrm{~m}$ long with $0.76-\mathrm{m}$-wide bed tops were formed on 1.5-m centers on 4 May 2019 or 22 Apr. 2020 using a custom bed shaper. To implement the flat bed treatments, a walk-behind tiller (BCS 739; BCS America, Oregon City, OR) was fitted with a hiller/furrower and axle extensions so that the tires would not compact the raised beds. The tiller was set to its most shallow depth, and the furrower was pulled behind the tiller to flatten the raised beds and create the flat bed treatment plots, moving the soil from the raised beds back into the furrows. This was done on 4 May 2019 or 23 Apr. 2020. Flat bed plots were immediately smoothed by hand with a garden rake after leveling. Whole plots (hybrid) were $17.1 \mathrm{~m}$ long, evenly divided into two subplots (seeding rate) and four total sub-subplots (bed shape; $4.3 \mathrm{~m}$ each). For $\approx 5$ weeks after creation of the bed treatments, the surface soil was allowed to weather into a fine seedbed because cultivation had created large aggregates. Nitrogen (N) fertilizer was added on 11 June 2019 or 28 May 2020 and incorporated with a walk-behind wheel hoe (Table 1). Nitrogen was applied as $25 \%$ urea-N and $75 \%$ slow-release ESN-N (Nutrien Ag Solutions, Saskatoon, Canada). Fertilizer rates were based on fertility recommendations (Rosen and Eliason, 2005).

'Morex' barley (Hordeum vulgare L.) was broadcast as a nurse crop at $55 \mathrm{~kg} \cdot \mathrm{ha}^{-1}$ on 13 June 2019 or 28 May 2020, and also lightly incorporated with a wheel hoe. Carrots were sown the following day. A Nibex 500 Precision Seeder (Andershonstein AB, Vetlana, Sweden) was calibrated for each hybrid and seeding rate (high or low). Seed suppliers recommended 555,750 to 741,000 per ha for 
Table 1. Soil and fertility conditions for carrot growth at the Southern Research and Outreach Center (Waseca, MN). Nutrients were all added preplant. The previous crop each year was spring wheat followed by fall fallow. Soil nitrogen and sulfur were not measured.

\begin{tabular}{|c|c|c|c|c|}
\hline \multirow[b]{2}{*}{$\begin{array}{l}\text { Soil parameter or nutrient } \\
\left(\mathrm{mg} \cdot \mathrm{kg}^{-1} \text {, unless noted) }\right.\end{array}$} & \multicolumn{2}{|c|}{2019} & \multicolumn{2}{|c|}{2020} \\
\hline & $\begin{array}{l}\text { Soil test } \\
\text { result }\end{array}$ & $\begin{array}{c}\text { Nutrient } \\
\text { added }\left(\mathrm{kg} \cdot \mathrm{ha}^{-1}\right)\end{array}$ & $\begin{array}{l}\text { Soil test } \\
\text { result }\end{array}$ & $\begin{array}{c}\text { Nutrient } \\
\text { added }\left(\mathrm{kg} \cdot \mathrm{ha}^{-1}\right)\end{array}$ \\
\hline$\overline{\mathrm{pH}}$ & 6.4 & - & 6.2 & - \\
\hline Organic matter $(\%)$ & 4.3 & - & 4.3 & - \\
\hline Nitrogen $(\mathrm{N})$ & - & 112 & - & 112 \\
\hline Phosphorus (Bray-1 P) & 24 & 37 & 17 & 49 \\
\hline Potassium $(\mathrm{K})$ & 158 & 70 & 154 & 70 \\
\hline Boron (B) & 0.676 & 1.1 & 0.658 & 1.1 \\
\hline Sulfur (S) & - & 11 & - & 11 \\
\hline
\end{tabular}

'Cupar' and $1,235,000$ to $2,099,500$ per ha for 'Envy' and 'Naval'. The hybrids used were recommended by the respective seed companies for productivity on mineral soils. A $35 \%$ greater population was targeted in the high seeding rate compared with low, and 'Cupar' was targeted at $44 \%$ of the seeding rate of 'Envy' or 'Naval'. Specifically, 'Cupar' was targeted at 592,800 or 800,280 viable seeds per ha, and 'Envy' and 'Naval' were targeted at $1,333,800$ or $1,803,100$ viable seeds per ha (low or high within cultivar, respectively). Seeding calculations were based on 1.5-m bed spacing. Supplier-provided values for viability and seed counts were used for planter calibration. Each plot was composed of three planted rows per bed (raised or flat), with outer rows $\approx 61 \mathrm{~cm}$ apart. Each outer row was targeted to contain $37.5 \%$ of the total seeding rate per meter of bed, and the inner row was targeted to receive $25 \%$ (outer rows were each $150 \%$ seeding rate of the inner rows). A $0.6-\mathrm{m}$ area was left between adjacent "hybrid" treatments to accommodate emptying and cleaning the planting boxes between hybrids. Each row was sown in a band using a $65-\mathrm{mm}$ scatter shoe.

Prowl $\mathrm{H}_{2} \mathrm{O}$ (38.7\% pendimethalin; BASF, Florham Park, NJ), AIM EC (22.3\% carfentrazone-ethyl; FMC, Philadelphia, PA), Roundup PowerMax (48.7\% glyphosate; Bayer, St. Louis, MO), Dakota (26.4\% clethodim; Rotam North America, Greensboro, NC), and Lorox (50\% linuron; NovaSource, Phoenix, AZ) herbicides were used for weed and barley control, in addition to hand-weeding. Carrots were sprayed twice per year with a total of 2.5 pounds of Kocide 3000 (46.1\% copper hydroxide; Certis USA, Columbia, MD) to

Table 2. Temperature and growing degree days accumulated during the 2019 and 2020 carrot-growing seasons.

\begin{tabular}{lccccccc}
\hline & \multicolumn{3}{c}{2019} & & \multicolumn{3}{c}{2020} \\
\cline { 2 - 4 } \cline { 6 - 8 } Days after seeding & Min. $^{\mathrm{z}}{ }^{\circ} \mathrm{C}$ & Max. $^{\mathrm{z}}{ }^{\circ} \mathrm{C}$ & GDD $_{5}{ }^{\mathrm{y}}$ & & Min. ${ }^{\circ} \mathrm{C}$ & Max. ${ }^{\circ} \mathrm{C}$ & GDD $_{5}$ \\
\hline $1-20$ & 13.3 & 31.7 & 327 & & 9.4 & 36.1 & 341 \\
$21-40$ & 12.2 & 33.9 & 358 & & 11.1 & 32.2 & 361 \\
$41-60$ & 9.4 & 30.0 & 323 & & 10.6 & 33.3 & 344 \\
$61-80$ & 7.8 & 28.3 & 267 & & 7.2 & 30.0 & 311 \\
$81-100$ & 7.8 & 30.6 & 289 & & 7.2 & 31.7 & 311 \\
$101+{ }^{\mathrm{x}}$ & 6.1 & 30.6 & & & 4.4 & 27.8 & \\
\hline
\end{tabular}

${ }^{\mathrm{z}}$ Minimum and maximum temperature recorded during the time period indicated.

${ }^{\mathrm{y}}$ Growing degree days (GDD) $\left(5^{\circ} \mathrm{C}\right.$ base temperature) accumulated during the time period indicated.

${ }^{\mathrm{x}}$ Temperature data recorded from $101 \mathrm{~d}$ after seeding until the final harvest. number and weight were calculated. "Large," "narrow," and "short" categories are similar to USDA topped carrot grades U.S. No. 1 Jumbo, U.S. Extra No. 1, and U.S. No. 2, respectively (USDA, 2020). Per-root fresh weight of largesize taproots was calculated from aggregate data.

Taproot length and maximum diameter were measured on a subsample of up to 10 randomly selected large-size taproots from each plot $\left(\mathrm{n}_{\text {min }}=3, \mathrm{n}_{\text {mean }}=9.2, \mathrm{n}_{\text {median }}=10\right)$ using a custom-made jig. The number measured was fewer than 10 for plots where fewer than 10 large-size taproots were harvested. Cylindricity was determined as described by Bleasdale and Thompson (1963), by individually dividing taproot fresh weight $(\mathrm{g})$ by the volume $\left(\mathrm{cm}^{3}\right)$ of a theoretical cylinder with diameter and length of each taproot $\left\{\mathrm{g} /\left[\pi \times{\text { (cm radius })^{2} \times}^{2}\right.\right.$ (cm length)]\}. Cylindricity is the percent of volume of the theoretical cylinder filled by the carrot (measured carrot density of 13 taproots was $1.001 \pm 0.017 \mathrm{~g} \cdot \mathrm{cm}^{-3}$ by water displacement at room temperature). Individual length, diameter, and cylindricity values were averaged per plot before analysis.

Soil penetration resistance was measured on 24 July 2019 or 20 July 2020 using a soil penetrometer (AgraTronix model 08180; AgraTronix, Streetsboro, OH). Two sets of penetration resistance measurements per plot were recorded on the same day at 7.6, 15.2, $22.9,30.5$, and $38.1 \mathrm{~cm}$. Weather data were collected on-site by National Weather Service station 218692 (Table 2, Fig. 1).

Statistics. Two 'Cupar' plots were removed from the analysis because the results recorded were clearly inaccurate $(>600,000$ marketable taproots per ha and $<100 \mathrm{~g}$ per large-size taproot, for example). Yield, size, and shape responses were subjected to mixed-model analysis of variance (ANOVA) using nlme::lme in $\mathrm{R}$ (Pinheiro et al., 2020; R Core Team, 2020). To accommodate the split-split plot design, the random intercept for all models was ( 1 year/block/hy$\mathrm{brid} / \mathrm{seeding}$ rate/bed). Fixed effects of hybrid $(\mathrm{n}=3)$, seeding rate $(\mathrm{n}=2)$, and bed $(\mathrm{n}=2)$ were included as full-factorial effects. Year was included as a random blocking effect and not a fixed effect because differences due to growing season were not of interest. The three categories of marketable carrots ("large," "narrow," and "short") were combined for marketable yield analyses, but "large" carrot yield (number and weight) was also analyzed independently. "Large" taproots as a percentage of total marketable taproots, and forked, bent, or cracked (unmarketable) taproots as a percent of total harvested taproots were analyzed also. Responses were transformed as needed to meet ANOVA assumptions (Tables 3 and 4). Interactions with Type II $P$ values $>$ 0.1 were removed to create reduced models, and the reduced models were compared with the full models using log-likelihood ratio tests (stats::anova; R Core Team, 2020).

To compare hybrids, Tukey's honestly significant difference comparisons were made between predicted means [emmeans::emmeans, Lenth (2020)]. Contrasts between predicted 


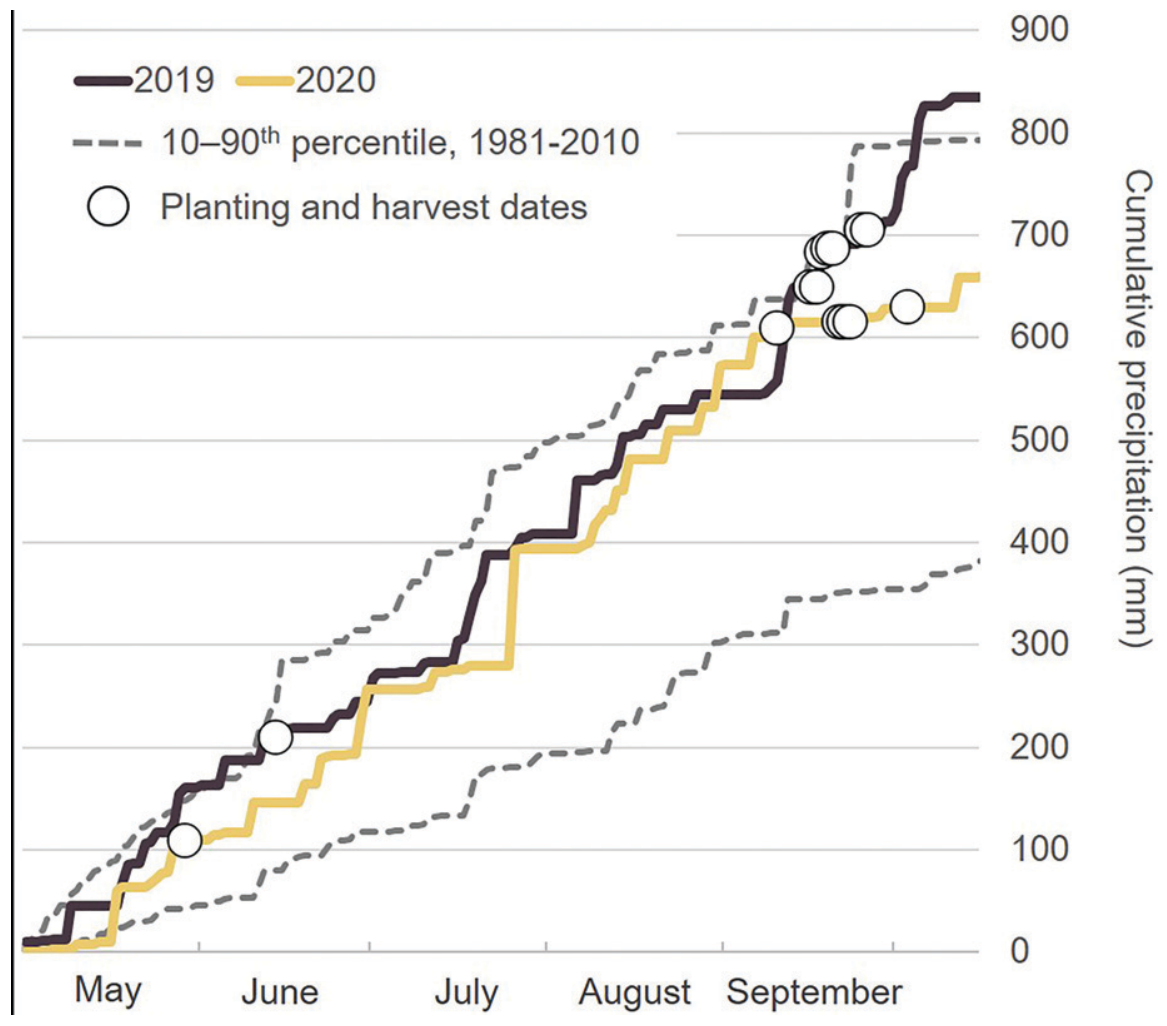

Fig. 1. Cumulative precipitation since 1 May recorded in 2019 and 2020, with historical 30-year 10th and 90th percentiles. Seeding and harvest dates in each year are indicated.

treatment means were also made using emmeans for seeding rate, bed, and significant $(P<0.05)$ interaction effects. Confidence intervals $(\mathrm{CI}, \pm 95 \%)$ of the difference between the treatment level (raised bed or high seeding rate) and the reference level (flat bed or low seeding rate) were back-calculated from transformed predicted differences and standard errors of the difference $[\mathrm{CI}=$ predicted mean difference $\pm 1.96 \times$ (standard error of the difference)].

To determine the Common Language (CL) effect size of raised beds (Lakens, 2013; McGraw and Wong, 1992), a Z-score was calculated from the difference of raw means and a correlation-adjusted pooled standard deviation:

$$
Z=\frac{\bar{y}_{\text {raised }}-\bar{y}_{\text {flat }}}{\sqrt{s_{\text {raised }}^{2}+s_{\text {flat }}^{2}+\left(2 r \times s_{\text {raised }} \times s_{\text {flat }}\right)}}
$$

where $\bar{y}$ is the raw group mean for raised beds or flat beds, $s$ is the raw sample standard deviation, and $r$ is the Pearson's correlation coefficient between paired bed types within a seeding rate subplot. Only paired data within subplots were used $(\mathrm{n}=68$ pairs used due to previously described data removal). The cumulative probability distribution greater than $Z$ in a unit normal distribution was calculated using Excel software [=norm.dist $(Z, 0,1)]$ to determine CL. CL was similarly calculated for the effect of high seeding rate, after averaging sub-subplot (bed) data within each seeding rate and removing incomplete pairs of subplots ( $n=34$ pairs used).
Soil penetration resistance at 7.6 and $15.2 \mathrm{~cm}$ was analyzed with mixed-model ANOVA, using bed type (flat or raised) and measurement depth as fixed effects. With two sets of measurements per plot, a within-plot random effect was included in addition to previously described random effects. Residual assumptions could not be satisfied for penetration resistance data beyond $15.2 \mathrm{~cm}$, so three separate Wilcoxon signed-rank tests were performed to test for soil penetration resistance on flat vs. raised beds at 22.9, 30.5, and $38.1 \mathrm{~cm}$ (stats::wilcox.test); the two penetration resistance values at each depth from each sub-subplot were averaged, and bed types (sub-subplots) within seeding rate were considered paired. $P$ values from the three tests were Holm-adjusted (stats::p.adjust).

To study direct effects of soil penetration resistance on parameters measured, simple linear models were made regressing normalized responses against penetration resistance at $7.6 \mathrm{~cm}$ (stats::1m). Responses were normalized before regression by dividing individual data by the maximum response within hybrid. Pearson correlation coefficients $(r)$ were calculated for estimating response to penetration resistance as well (stats::cor.test).

\section{Results and Discussion}

Precipitation was within expected ranges for much of both years (Fig. 1). However, in 2019, two separate 6-day periods with more than 100 $\mathrm{mm}$ were recorded. And 4 (nonconsecutive) days in 2020 experienced 39 to $112 \mathrm{~mm}$ of rainfall. Temperature and growing degree days from each year are reported in Table 2 .

In reporting results from two-level factors (seeding rate and bed shape), we report the mean of the reference level (either low seeding rate or flat bed) and the CI of the difference from the reference level. This is done to illustrate the magnitude and direction of the effect, not just the distribution of the measured responses (raw standard error or $\mathrm{CI}$ ) at each level of the factor. In addition, a Common Language effects size (CL) is reported for seeding rate and bed effects in Tables 3 and 4 . The CL for the effect of high seeding rate on the number of marketable taproots per ha, for example, is $66 \%$ (Table 3). This means that a randomly selected sample from the high seeding rate treatment has a $66 \%$ chance of having more marketable taproots than a randomly selected sample from the low seeding rate treatment. Similarly, a randomly selected sample from the raised bed treatment has a $34 \%$ chance of being largerdiameter than a randomly selected sample from the flat bed treatment (Table 4). The CI of the difference and CL are measures that improve understanding of how meaningful the responses are in the current study, and are tools for understanding this research in the context of similar work (Kramer et al., 2019; Nakagawa and Cuthill, 2007).

A mixed-effect ANOVA model with only hybrid and seeding rate as fixed main effects explained variation in the total number of taproots harvested (marketable and unmarketable) equally as well as a full-factorial model that included bed shape $\left(\Lambda_{8}=7.34, P=0.50\right)$. 
Table 3. Comparisons of a mixed-effect analysis of variance reduced model to a full-factorial model for each of the carrot taproot yield responses measured. Transformation used for each response is indicated, as well as Wald $\chi^{2}$ (Type II) $P$ values for each of the fixed effects remaining in the reduced model: carrot hybrid $(n=3)$, seeding rate $(\mathrm{sr}, \mathrm{n}=2)$, bed shape $(\mathrm{n}=2)$, and interactions. Akaike's information criterion (AIC) is reported for full and reduced models. Factors with $P<0.05$ are highlighted in bold. Common Language effects size (CL) of raised beds or high seeding rate is reported. A log-likelihood ratio test statistic $\left(\Lambda_{\mathrm{df}}\right)$, comparing the reduced to the full model, is reported with $P$ value and df. Misshapen taproots include those that were forked, bent, or cracked.

\begin{tabular}{|c|c|c|c|c|c|c|c|}
\hline Transformation & $\begin{array}{c}\text { Full factorial } \\
\text { AIC }\end{array}$ & \multicolumn{3}{|c|}{ Reduced model } & CL (\%) & \multicolumn{2}{|c|}{ Model comparison (reduced vs. full) } \\
\hline$\sqrt{y}$ & 754.9 & 744.6 & $\begin{array}{l}\quad \text { Marketable } \\
\text { hybrid } \\
\text { seeding rate } \\
\text { bed }\end{array}$ & $\begin{array}{r}\text { oots (tho } \\
<\mathbf{0 . 0 0 1} \\
\mathbf{0 . 0 0 4} \\
0.915\end{array}$ & $\begin{array}{c}\text { ind per ha) } \\
66 \% \\
50 \%\end{array}$ & $\Lambda_{7}=3.69$ & 0.815 \\
\hline none & 1115.9 & 1110.1 & $\begin{array}{l}\quad \text { Marketa } \\
\text { hybrid } \\
\text { seeding rate } \\
\text { bed }\end{array}$ & $\begin{array}{r}\text { taproots } \\
0.235 \\
0.577 \\
\mathbf{0 . 0 0 8}\end{array}$ & $\begin{array}{r}\left.g \cdot h a^{-1}\right) \\
46 \% \\
62 \%\end{array}$ & $\Lambda_{7}=8.12$ & 0.322 \\
\hline$\sqrt{y}$ & -262.0 & $\begin{array}{l}\text { Market } \\
-271.0\end{array}$ & $\begin{array}{l}\text { taproots ( } \mathrm{n} \text { as } \\
\text { hybrid } \\
\text { seeding rate } \\
\text { bed }\end{array}$ & $\begin{array}{r}\text { percentag } \\
<\mathbf{0 . 0 0 1} \\
0.074 \\
0.265\end{array}$ & $\begin{array}{c}\text { f all harves } \\
\text { 37\% } \\
56 \%\end{array}$ & s) $\Lambda_{7}=5.02$ & 0.658 \\
\hline$\sqrt{y}$ & 754.7 & 750.7 & $\begin{array}{l}\text { Large-size } \\
\text { hybrid } \\
\text { seeding rate } \\
\text { bed } \\
\text { hybrid } \times \text { bed }\end{array}$ & $\begin{array}{r}\text { oots (tho } \\
<\mathbf{0 . 0 0 1} \\
0.405 \\
\mathbf{0 . 0 0 2} \\
0.053\end{array}$ & $\begin{array}{c}\text { nd per ha) } \\
\qquad \begin{array}{c}42 \% \\
65 \%\end{array}\end{array}$ & $\Lambda_{5}=6.03$ & 0.303 \\
\hline$\sqrt{y}$ & 461.6 & 457.8 & $\begin{array}{l}\quad \text { Large-si } \\
\text { hybrid } \\
\text { seeding rate } \\
\text { bed } \\
\text { hybrid } \times \text { bed } \\
\text { bed } \times \text { sr }\end{array}$ & $\begin{array}{r}\text { taproots } \\
0.672 \\
\mathbf{0 . 0 4 7} \\
<\mathbf{0 . 0 0 1} \\
0.060 \\
0.083\end{array}$ & $\begin{array}{r}\left(\mathrm{a}^{-1}\right) \\
\\
35 \% \\
67 \%\end{array}$ & $\Lambda_{4}=4.22$ & 0.377 \\
\hline
\end{tabular}

The reduced model was then compared with a model in which 'Envy' and 'Naval' results were grouped together, because they were planted at the same seeding rates. This model (reduced and grouped) performed equally as well as the reduced model alone $\left(\Lambda_{1}=0.02\right.$, $P=0.88$ ), and AIC (Akaike information criterion) was improved at each step. Compared with 'Envy' and 'Naval' (928,776 per ha), the relative proportion of total carrots harvested in 'Cupar' was $38 \%$ to $45 \%(95 \% \mathrm{CI})$; the target ratio was $44 \%$ at seeding. At high seeding rate, $23 \%$ to $43 \%$ more total carrots were harvested than at low seeding rate $(517,792$ per ha); the target ratio was $35 \%$. Though the relative amounts of harvested plants were within the targeted ranges, the absolute number of harvested taproots was far lower than what was planted. Stand counts and germination were not recorded, so the mechanism of this loss is unknown.

The overall average marketable yield was 34.5 $\mathrm{Mg} \cdot \mathrm{ha}^{-1}$, which was less than the $54.5 \mathrm{Mg} \cdot \mathrm{ha}^{-1}$ reported from Wisconsin in 2019 (USDA NASS, 2020) and less than the yield goal of $44.9 \mathrm{Mg} \cdot \mathrm{ha}^{-1}$ described in
University of Minnesota fertility recommendations (Rosen and Eliason, 2005). However, carrots in this study were sorted according to fresh-market standards, not processing standards. Regional yield estimates for small-scale fresh-market production are as low as 10 to $15 \mathrm{Mg} \cdot \mathrm{ha}^{-1}$ (Delahaut and Newenhouse, 2011), and the national average for freshmarket yield from 2010 to 2015 was 34.3 to $39.5 \mathrm{Mg} \cdot \mathrm{ha}^{-1}$ (USDA NASS, 2020). We therefore realized a reasonable fresh-market yield. The number of marketable taproots and large-size taproots was greater in 'Envy' and 'Naval' compared with 'Cupar', but there were no differences in marketable $\mathrm{Mg}$ yield among the hybrids (Table 3, Fig. 2) because of the greater large-size taproot diameter and weight of 'Cupar' (Table 4, Fig. 3). A greater percentage of taproots were unmarketable in 'Envy' and 'Naval' (Fig. 2).

The largest impacts of raised beds on yield responses were related to the number and total weight of large-size taproots. There were 10,984 to $54,656(95 \% \mathrm{CI})$ more largesize taproots per ha from raised beds (CL $=$ $65 \%$; Table 3, Fig. 4), and 2.0 to 7.3 (95\%
CI) more $\mathrm{Mg} \cdot \mathrm{ha}^{-1}$ of large-size taproots from raised beds $(\mathrm{CL}=67 \%$; Table 3 , Fig. 4 ). The increase in number of large-size taproots due to raised beds was largely driven by 'Naval' (interaction $P=0.053$; Table 3). 'Cupar' realized an average gain of $14 \%$ more large-size taproots due to raised beds, 'Envy' had 4\% more, but 'Naval' had 41\% more large-size taproots on raised beds compared with flat beds (not shown). An increase due to raised beds of $10.6 \%$ in total fresh weight of marketable taproots of all sizes was measured ( $\mathrm{CL}=62 \%$; Table 3, Fig. 4), but this was less substantial than the increase in large-size taproots. There was no impact of raised beds on the total number of marketable taproots $(\mathrm{CL}=50 \%$; Table 3, Fig. 4).

Raised beds did not impact average length of large-size taproots (CL $=55 \%$; Table 4 , Fig. 4); however, raised beds increased the proportion of large-size taproots $(95 \% \mathrm{CI}=$ $4.7 \%-13.4 \%$ greater percentage of large-size taproots from raised beds, $\mathrm{CL}=68 \%$; Table 3 , Fig. 5). The fact that the total number of marketable taproots did not increase due to raised beds, but weight of marketable taproots and 
Table 4. Comparisons of a mixed-effect analysis of variance reduced model to a full-factorial model for each of the carrot taproot shape and size responses measured. A log-likelihood ratio test statistic $\left(\Lambda_{\mathrm{df}}\right)$, comparing the reduced to the full model, is reported with $P$ value and df. Akaike's information criterion (AIC) is reported for full and reduced models. Measurements were made on up to 10 large-size marketable carrots per plot, and arithmetic per-plot mean was analyzed. Cylindricity is $\mathrm{g}$ per taproot as a fraction of maximum possible taproot volume $\left(\mathrm{cm}^{3}\right)$ per carrot. Transformation used for each response is indicated, as well as Wald $\chi^{2}$ (Type II) $P$ values for each of the fixed effects remaining in the reduced model: carrot hybrid $(\mathrm{n}=3)$, seeding rate $(\mathrm{sr} ; \mathrm{n}=2)$, bed shape $(\mathrm{n}=2)$, and interactions. Factors with $P<0.05$ are highlighted in bold. Common Language effects size (CL) of raised beds or high seeding rate is reported.

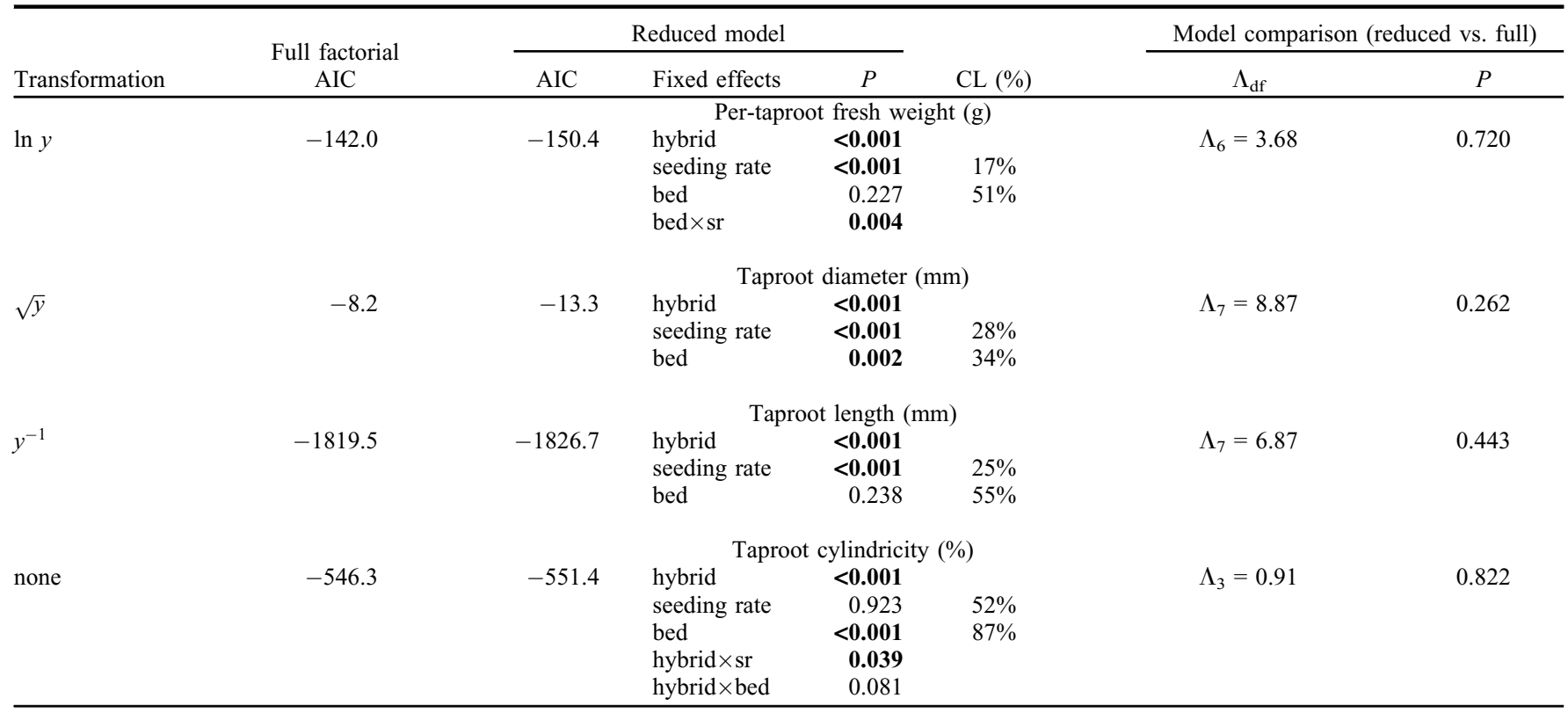

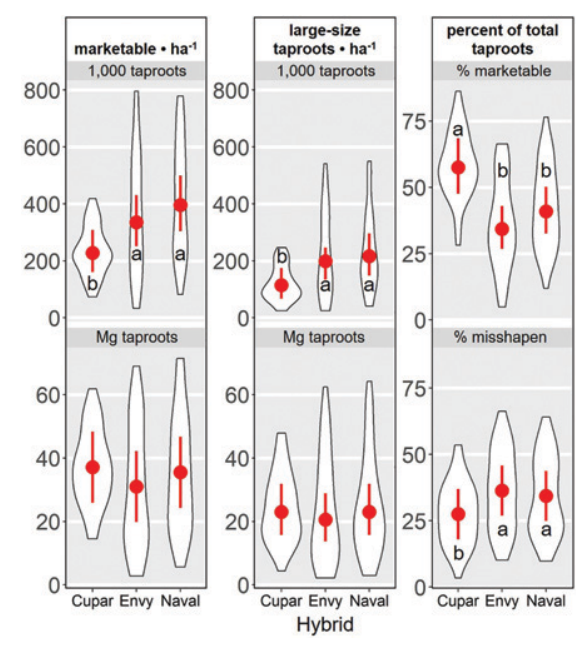

Fig. 2. Carrot taproot yield parameters measured in three hybrids: 'Cupar', 'Envy', and 'Naval'. The number and total weight of marketable taproots, number and total weight of large-size taproots ( $\geq 127 \mathrm{~mm}$ long, $\geq 25 \mathrm{~mm}$ diameter), and the percentage of all taproots that were marketable or misshapen (forked, bent, or cracked) were measured. Violin plots illustrate distribution of data, data points indicate predicted mean, and bars represent $\pm \mathrm{SE}$ of predicted mean. Data with different letters indicate statistical differences based on Tukey's honestly significant difference $(\alpha=0.05)$, and lack of letters indicates lack of statistical significance.

total weight and number of large-size taproots did increase, led to a reasonable conclusion that "short" marketable taproots (76-127 $\mathrm{mm})$ were able to achieve greater length $(\geq 127 \mathrm{~mm})$ on raised beds compared with flat beds, thus explaining the increase in

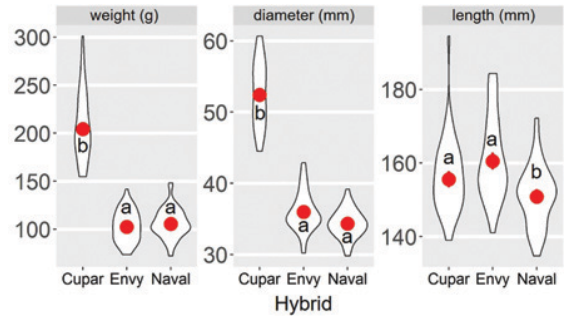

Fig. 3. Size of large-size carrot taproots $(\geq 127$ $\mathrm{mm}$ long, $\geq 25 \mathrm{~mm}$ diameter) measured in three hybrids: 'Cupar', 'Envy', and 'Naval'. Violin plots illustrate distribution of data, data points indicate predicted mean, and bars represent \pm SE of predicted mean. Bars may be obscured by the mean. Data with different letters indicate statistical differences based on Tukey's honestly significant difference $(\alpha=$ 0.05 ), and lack of letters indicates lack of statistical significance.

proportion of "large" taproots. The fact that an increase in length of large-size taproots was not detected from raised beds obscures the increase in overall average length of marketable taproots.

The average fresh weight of large-size taproots grown on flat beds at high seeding rate was lower than fresh weight on flat beds at low seeding rate, but the seeding rate impact was not as great on raised beds (interaction $P=0.004$; Table 4, Fig. 6). At low seeding rate, large-size taproot weight was not changed by growing carrots on raised vs. flat beds (Fig. 4). If one is interested in greater fresh weight per large-size taproot, high seeding rate, especially without raised beds, should be avoided. Although $23 \%$ to $43 \%$ more total taproots were harvested under high seeding rate, only $5 \%$ to $30 \%$ more marketable taproots were harvested with high seeding rate $(\mathrm{CL}=66 \%$; Table 3, Fig. 6). There was no less total marketable weight when seeding rate was high compared with low $(\mathrm{CL}=46 \%$; Table 3, Fig. 6 ), we found more total marketable taproots due to high seeding rate, and there were no differences in the number of large-size taproots due to high seeding rate compared with low seeding rate $(\mathrm{CL}=42 \%$; Table 3, Fig. 6). However, a lower percentage of marketable carrots were "large" size when grown at high seeding rate compared with low seeding rate $(\mathrm{CL}=21 \%$; Table 3, Fig. 5). We therefore conclude that high seeding rate caused smaller, more numerous marketable taproots. This is also supported by the smaller diameter $(\mathrm{CL}=28 \%)$ and shorter length $(\mathrm{CL}=25 \%)$ of large-size taproots at high seeding rate (Table 4, Fig. 6). Previous research has shown similar results. Taproot length was reduced under elevated population density in 'Amsterdam Forcing' and 'Autumn King' (Thompson, 1969).

It is possible that a limit to length of carrots in our soil was reached, as the maximum plot average of large-size carrots in our study was $195 \mathrm{~mm}$. This was reported in a 'Cupar' plot that had the fewest total roots harvested (Fig. 3). There was no difference in length between large-size 'Cupar' and 'Envy' (Fig. 3 ), although 'Cupar' is reported by the breeder to grow to $\approx 200 \mathrm{~mm}$ and 'Envy' is reported to grow to $\approx 280 \mathrm{~mm}$. 'Cupar' did have a lower percentage of large-size taproots compared with 'Envy' (Fig. 5), but perhaps growing seasons were not long enough in this study (94-116 d, 1454-1808 $\mathrm{GDD}_{5}$; growing degree days, $5{ }^{\circ} \mathrm{C}$ base 


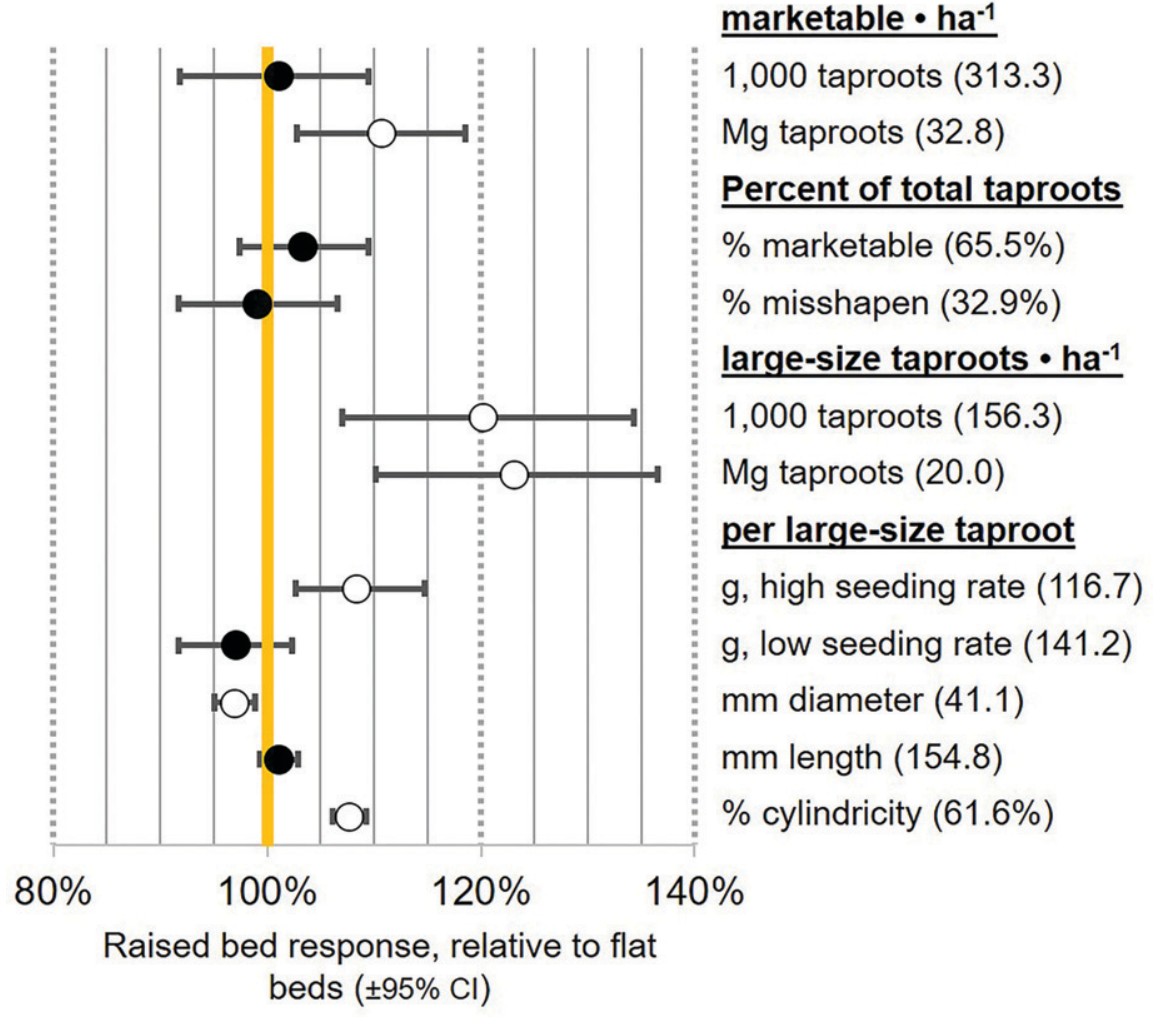

Fig. 4. Effect size of raised beds on carrot taproot yield and size parameters; $100 \%$ (vertical yellow line) represents the predicted mean of flat beds, circles represent predicted mean difference of carrots grown on raised beds, and error bars are the $\pm 95 \%$ confidence intervals of the difference from flat beds. Treatments with error bars that do not overlap the flat bed mean indicate no difference between flat and raised beds (closed circles, contrast $P>0.05$ ). Flat bed means for each parameter are indicated parenthetically. Large-size taproots were $\geq 127 \mathrm{~mm}$ long, $\geq 25 \mathrm{~mm}$ diameter. Cylindricity is the volume filled by the taproot compared with a cylinder of the same diameter and length as the taproot.

\section{Size category: narrow $\square$ short $\square$ large}

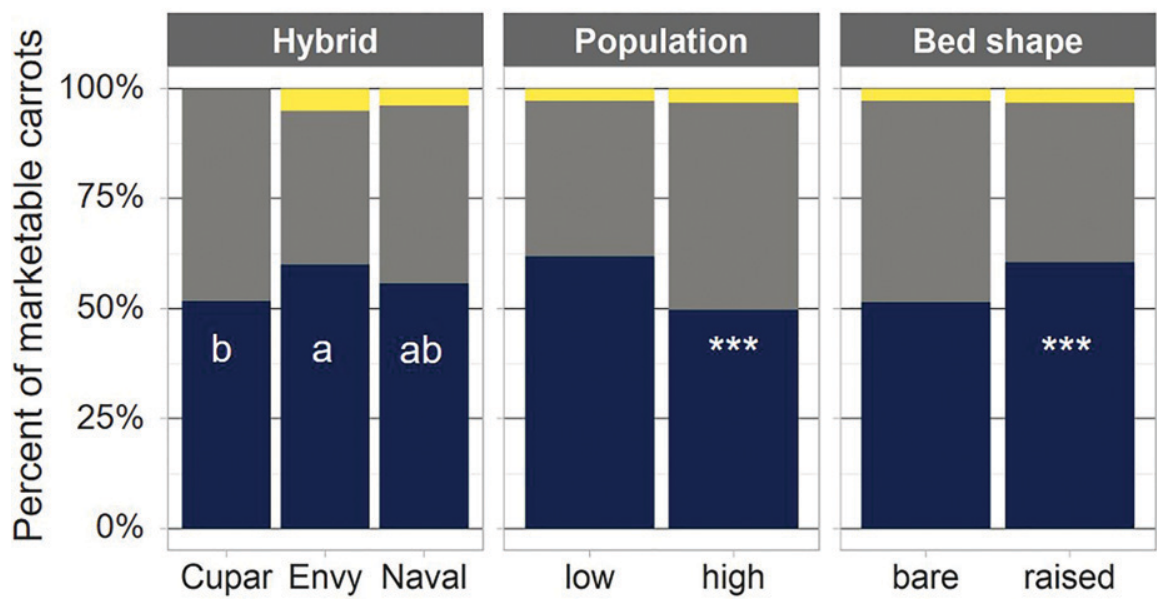

Fig. 5. Percentage of harvested carrot taproots in each marketable size category depending on hybrid, seeding rate, and bed shape. Hybrids with the same letter do not have a different percentage of large-size taproots based on Tukey's honestly significant difference $(\alpha=0.05)$. ***Treatment effect on the percentage of large-size taproots is different from the reference level $(P<0.001)$.

temperature), especially for 'Envy' to reach its full potential. 'Envy' is described by the breeder as an early- to midseason hybrid, and 'Cupar' (104-111 d, 1671-1691 $\left.\mathrm{GDD}_{5}\right)$ is described as midlate. 'Naval' $\left(103-115 \mathrm{~d}, 1599-1794 \mathrm{GDD}_{5}\right)$ is also described as midlate and $\approx 229 \mathrm{~mm}$, but large- size 'Naval' were shorter in this study than either 'Envy' or 'Cupar' (Table 4, Fig. 3).

Overall soil penetration resistance in this study was relatively low at all depths and in both bed types. Eighty-nine percent of soil penetration resistance measurements at 15.2 $\mathrm{cm}$ depth were $<1 \mathrm{MPa}$, and average penetration resistance beyond $15.2 \mathrm{~cm}$ was $0.77 \mathrm{MPa}$ (not shown). In one study, penetration resistance in noncompacted, $30 \%$ clay soil was $1.4 \mathrm{MPa}$ at 7.0 to $17.5-\mathrm{cm}$ depth (Pietola, 1995). In that study, 158-mm taproots were grown with no imposed compaction treatment (cv. Nantes Duke Notabene $370 \mathrm{~Sv}$ ), which is similar to lengths of largesize carrots recorded in our study (Fig. 3).

Penetration resistance at 7.6 and $15.2 \mathrm{~cm}$ soil depth was lower on raised beds compared with flat beds (interaction $P<0.001$; Fig. 7). At $7.6 \mathrm{~cm}$, penetration resistance was $33 \%$ lower on raised beds compared with flat beds (paired CL for flat-raised $=20 \%, \mathrm{n}=72$ ). At $15.2 \mathrm{~cm}$, penetration resistance was $9.8 \%$ lower $(\mathrm{CL}=38 \%)$. Wilcoxon signed-rank tests from deeper penetrometer readings revealed no penetration resistance difference between bed shapes at these depths (not shown).

To explore soil compaction as a mechanism of the bed shape effects, yield and shape responses were regressed against penetration resistance at $7.6 \mathrm{~cm}$ soil depth. First, responses were normalized within hybrid by dividing each data point by the maximum value within each hybrid. This was done because of significant hybrid effects for some responses, and a correlation coefficient and slope independent of hybrid was desirable. Then, due to correlation between numerous yield responses (Fig. 8), a "combined yield response" was created. This was the average of the normalized responses for $\mathrm{Mg}$ marketable taproots per ha, $\mathrm{n}$ and $\mathrm{Mg}$ large-size taproots per ha, percentage of taproots that were marketable, and (100 percent of taproots that were misshapen). These responses were all highly positively correlated $(0.63 \leq r \leq 0.93$; Fig. 8$)$.

The combined yield response showed a substantial decrease as soil penetration resistance at $7.6 \mathrm{~cm}$ increased (Fig. 9). The number of taproots that were marketable showed a similar, but less severe response (shallower slope) to soil penetration resistance (Fig. 9). Maximizing carrot yield clearly requires limiting compaction, at least in the top $7.6 \mathrm{~cm}$ of soil, which is supported by previous research (Johansen et al., 2015). Reducing compaction up to $15.2 \mathrm{~cm}$ by creating raised beds is a reasonable mechanism for increasing carrot yield. What is unclear in this study is how raised beds were unable to decrease the percentage of taproots that were forked, bent, or cracked $(\mathrm{CL}=49 \%, P=0.83$; Table 3, Fig. 4) even though soil penetration resistance was positively correlated with the normalized percentage of misshapen taproots $(P<0.001$, $r=0.39$; data not shown), and compaction substantially increased percentage of forked and split roots in a previous study (Pietola, 1995).

Variation in cylindricity of large-size taproots was largely determined by hybrid and bed shape Table 4). Cylindricity was $61.6 \%$ on flat beds and $66.3 \%$ on raised beds $(\mathrm{CL}=$ $87 \%$; Table 4, Fig. 4). The effect of raised beds on cylindricity was slightly greater in 'Envy' and 'Naval' compared with 'Cupar' (interaction $P=0.081$; Table 4), and 'Naval' was far more cylindrical on average than 


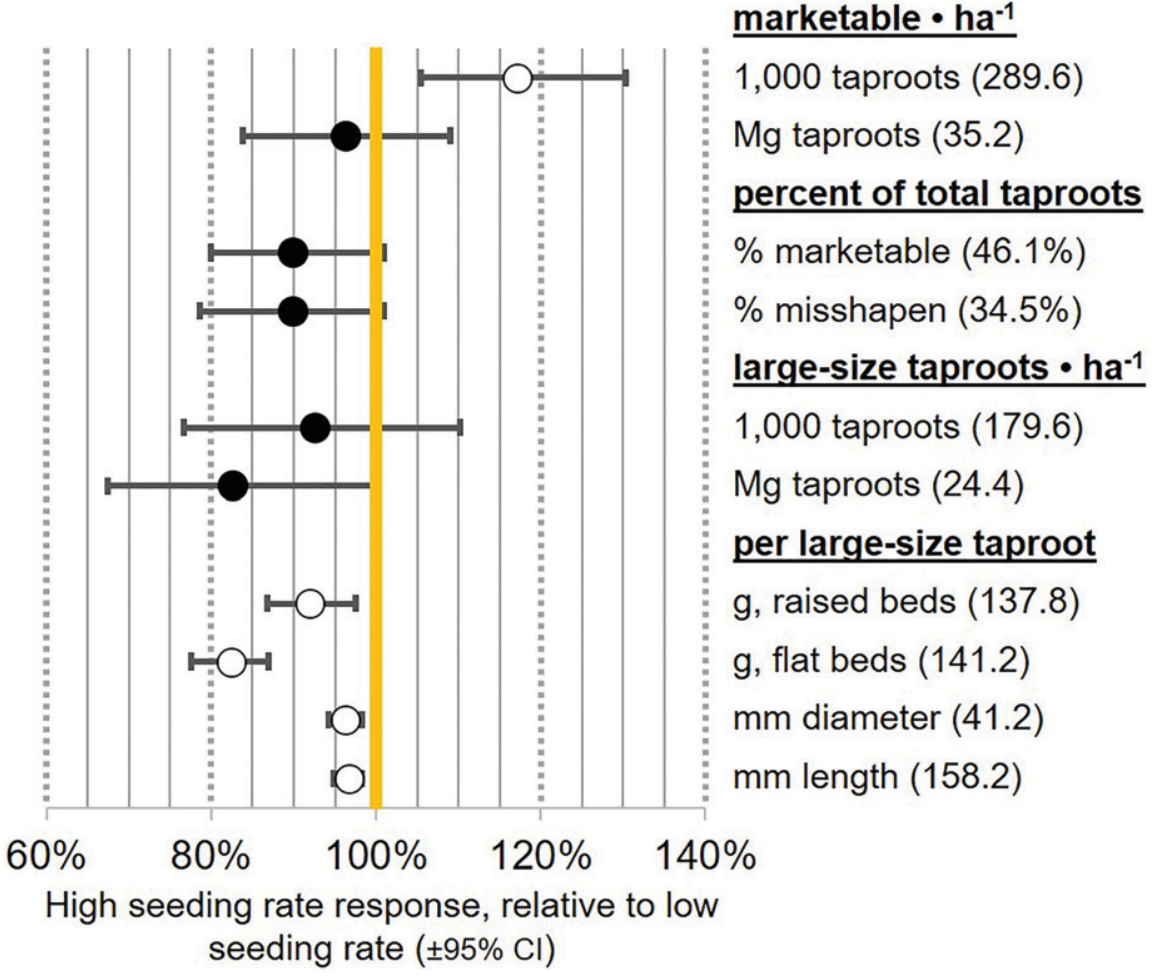

Fig. 6. Effect size of high seeding rate on carrot taproot yield and size parameters; $100 \%$ (vertical yellow line) represents the predicted mean of low relative seeding rate, circles represent predicted mean difference of high seeding rate, and error bars are the $\pm 95 \%$ confidence interval of the difference from low seeding rate. Treatments with error bars that do not overlap the low seeding rate mean indicate no difference between low and high seeding rate (closed circles, contrast $P>0.05$ ). Low seeding rate means for each parameter are indicated parenthetically. Large-size taproots were $\geq 127 \mathrm{~mm}$ long, $\geq 25 \mathrm{~mm}$ diameter.

'Cupar' or 'Envy' (Fig. 10). Nantes-type carrots, like 'Naval', are identified by their cylindrical shape and blunt taproot tip. Seeding rate had no effect on cylindricity within 'Cupar', and there was a trend for contrasting seeding

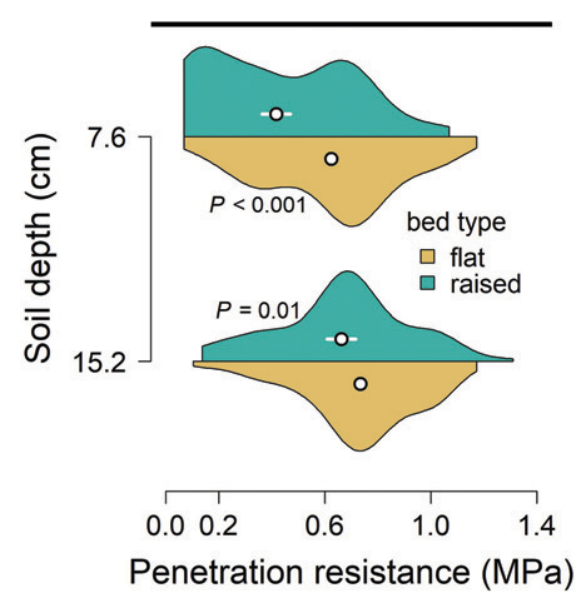

Fig. 7. Soil penetration resistance at 7.6 or 15.2 $\mathrm{cm}$ from the surface, measured by a soil penetrometer. Soil was either flat beds or $\approx 7.6-\mathrm{cm}$ raised beds. Data are from July 2019 and 2020. Violin plots illustrate distribution of data, circles indicate predicted mean, and error bars represent the $95 \%$ confidence intervals of the difference between bed types. Within-depth significance level ( $P$ value) of contrasts between predicted means of each bed type is shown. rate effects in 'Envy' and 'Naval' (interaction $P=0.039$; Table 4, Fig. 10). Cylindricity of large-size taproots decreased slightly as penetration resistance increased, but the correlation was robust (Fig. 9). This response has been noted in previous research (Johansen et al., 2015). The decrease in large-size taproot cylindricity associated with soil penetration resistance and raised beds could be explained by a soil compaction-induced increase in diameter with no change in length or fresh weight of large-size taproots (Table 4, Figs. 4 and 9).

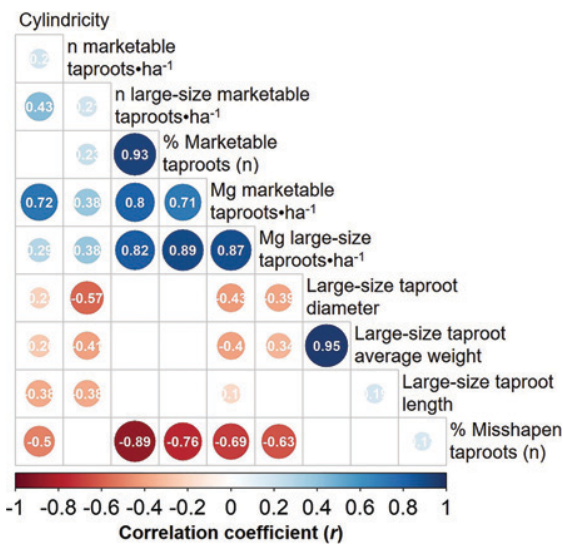

Fig. 8. Pearson's correlation between measured carrot responses. Correlation coefficient $(r)$ value is displayed, and also represented by color and circle size. Only correlations with $P>0.05$ are shown.
We did not study organoleptic properties or chemical constituents of carrots, but one study found compaction-induced reduction in cylindricity was related to reduced quality of color and texture (Taksdal, 1984).

The Nicollet soil used in this study is classified as fine clay loam. Clay loam soils are less compressible than sandy or silty loam soils (Warren and Taylor, 2014) that are commonly used for carrot production in the Midwest. It is possible that more extreme effects of raised beds might be seen on more compressible soils, or on taller raised beds than were made here. However, one previous study found compaction treatments had a more detrimental effect on carrot yield and size in clay soil than in a sandy soil (Pietola, 1995). Soil moisture characteristics were not studied here, but higher water-holding capacity of the clay-loam soil also may have reduced yield compared with coarse-texture or peat/muck soil. A greenhouse study using muck soil found more available water caused shorter carrot length and reduced yield

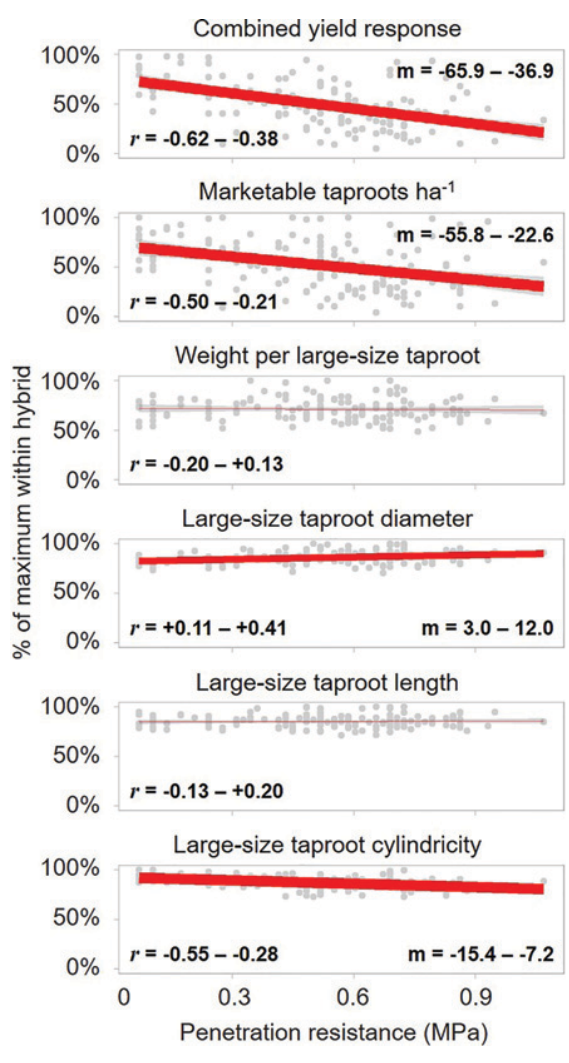

Fig. 9. Response of carrot taproot yield, size, and shape parameters to soil penetration resistance (MPa) at $7.6-\mathrm{cm}$ depth. All values were normalized to $\%$ of maximum value within each hybrid before analysis. Combined yield response is the per-plot average of Mg marketable taproots per ha, $\mathrm{n}$ and $\mathrm{Mg}$ large-size taproots per ha, percentage of taproots that were marketable, and (100 - percent of taproots that were misshapen), all normalized within hybrid. The width of the red regression line is proportional to $(1-P$ value $)$ for the simple linear model. The $95 \%$ confidence interval (CI) for the correlation between penetration resistance and response is reported $(r)$, and regression slope $(\mathrm{m}) 95 \% \mathrm{CI}$ is reported for regressions with $P<0.01$. 


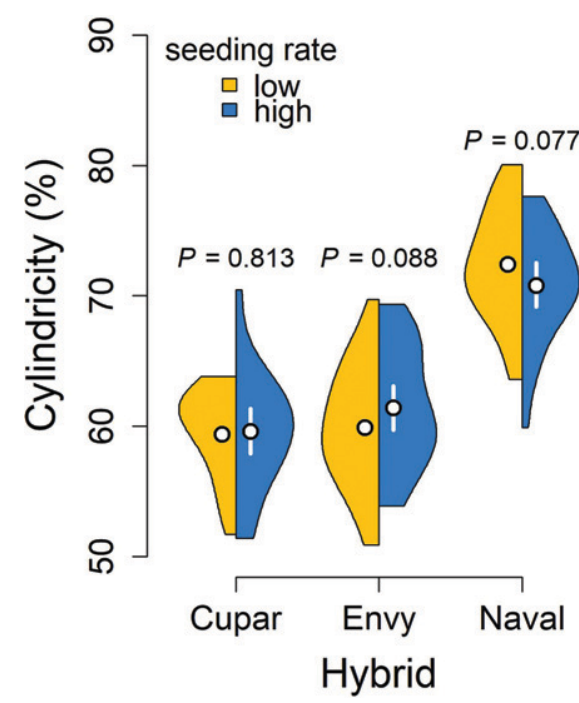

Fig. 10. Carrot seeding rate effects on taproot cylindricity in three carrot hybrids. Cylindricity is the volume filled by the taproot compared with a cylinder of the same diameter and length as the taproot. Violin plots illustrate distribution of data, circles indicate predicted mean, and error bars represent the $95 \%$ confidence interval of the difference between seeding rates within hybrid. Within-hybrid significance level $(P$ value $)$ of contrasts between predicted means of each bed type is shown.

compared with a moderate amount of available water (White, 1992).

The larger diameter and greater taper (lower cylindricity) of 'Cupar' made this hybrid easier to harvest by hand compared with 'Envy' or 'Naval' (personal observation). Soil conditions for harvest in the clay-loam soil were not always ideal (especially in very wet or dry periods), and 'Cupar' could sometimes be harvested simply by pulling taproots from loosened soil by their tops. This was not typically the case with 'Envy' or 'Naval'. The latter two tended to break below ground if the soil was not loosened deeply enough, which was less of an issue with 'Cupar'. This benefit likely extends to other Chantenaytype carrots, with less-cylindrical and largerdiameter taproots. And if this anecdotal evidence holds true, it may be that carrots grown at lower seeding rate are easier to hand-harvest due to reduced cylindricity and increased diameter, with no effects on total yield except for number of marketable roots. However, lower seeding rates may create challenges with weed control (Colquhoun et al., 2020). Increasing the number of rows per bed, rather than plants per row, may be an optimum strategy for weed control and maintenance of taproot size and yield (Colquhoun et al., 2020).

In conclusion, raised beds are an effective measure to increase total yield of carrots in clay-loam soil, and cultivar selection can be a useful tool for maximizing efficiency of producing large-size fresh-market carrots, especially with cultivar-appropriate seeding rates.

\section{Literature Cited}

Bakker, D.M., G.J. Hamilton, D.J. Houlbrooke, and C. Spann. 2005. The effect of raised beds on soil structure, waterlogging, and productivity on duplex soils in Western Australia. Austral. J. Soil Res. 43:575-585, doi: 10.1071/SR03118.

Bleasdale, J.K.A. and R. Thompson. 1963. An objective method of recording and comparing the shapes of carrot root. J. Hort. Sci. 38:232-241, doi: 10.1080/00221589.1963.11514074.

Brown, P. and A. Gracie. 2000. Factors influencing carrot size and shape. Publication VG97019. Horticulture Austral. Limited, Sydney, NSW.

Colquhoun, J.G., R.A. Rittmeyer, and D.J. Heider. 2020. A holistic carrot production system for season-long weed management. Weed Technol. 34:876-881, doi: 10.1017/wet.2020.84.

Delahaut, K.A. and A.C. Newenhouse. 2011 Growing carrots, beets, radishes, and other root crops in Wisconsin: A guide for fresh-market growers. UW-Extension publication A3686.

Jauron, R. and G. Wallace. 2017. Yard and garden: Planting carrots in the home garden. 28 Jan. 2021. $<$ https://www.extension.iastate.edu/news/yardand-garden-planting-carrots-home-garden $>$.

Johansen, T.J., M.G. Thomsen, A.-K. Løes, and H. Riley. 2015. Root development in potato and carrot crops - influences of soil compaction. Acta Ag. Scandinavica B. 65(2):182-192, doi: 10.1080/09064710.2014.977942.

Kelley, W.T. and S.C. Phatak. 2009. Commercial production and management of carrots. Univ. Ga. Ext. Bul. 1175.

Kramer, M.H., E.T. Paparozzi, and W.W. Stroup. 2019. Best practices for presenting statistical information in a research article. HortScience 54(9):1605-1609, doi: 10.21273/HORTSCI139 52-19.

Lakens, D. 2013. Calculating and reporting effect sizes to facilitate cumulative science: A practi- cal primer for t-tests and ANOVAs. Front. Psychol. 4:1-12, doi: 10.3389/fpsyg.2013.00863.

Lenth, R.V. 2020. Emmeans: Estimated marginal means, aka least-squares means. $\mathrm{R}$ package version 1.5.3. <https://CRAN.R-project.org/ package $=$ emmeans $>$.

McGraw, K.O. and S.P. Wong. 1992. A common language effect size statistic. Psychol. Bull. 111(2):361-365, doi: 10.1037/0033-2909.111. 2.361 .

Nakagawa, S. and I.C. Cuthill. 2007. Effect size, confidence interval and statistical significance: A practical guide for biologists. Biol. Rev. Camb. Philos. Soc. 82:591-605, doi: 10.1111/j.1469185X.2007.00027.x.

Pietola, L. 1995. Effect of soil compactness on the growth and quality of carrots. Agr. Sci. Finland 4:144-237, doi: 10.23986/afsci.72611.

Pinheiro, J., D. Bates, S. DebRoy, D. Sarkar, and R Core Team. 2020. nlme: Linear and nonlinear mixed effects models. $\mathrm{R}$ package version 3.1151. $<$ https://CRAN.R-project.org/package $=$ nlme $>$.

Rosen, C.J. and R. Eliason. 2005 Nutrient management for commercial fruit and vegetable crops in Minnesota. University of Minnesota Extension Service, St. Paul, MN. <https://hdl.handle. net/11299/197955>

R Core Team. 2020. R: A language and environment for statistical computing. R Foundation for Statistical Computing, Vienna, Austria. $<$ https://www.R-project.org/>.

Smetanka, M.J. 2017. Eager to get growing? Many root vegetables can be sown in April. The Star Tribune, Minneapolis, MN. 29 Jan. 2021. $<$ https://www.startribune.com/what-can-youplant-now-root-vegetables/417806233/>.

Taksdal, G. 1984. Effect of tractor wheelings on carrot quality. Acta Hort. 163:255-260.

Thompson, C. 2017. Carrots provide benefits for small scale growers. Vegetable Grower News, Sparta, MI. 28 Jan. 2021. < https://vegetable growersnews.com/news/carrots-provide-benefitssmall-scale-growers/>

Thompson, R. 1969. Some factors affecting carrot root shape and size. Euphytica 18:277-285.

USDA. 2020. United States standards for grades of topped carrots. <http://www.ams.usda.gov/sites/ default/files/media/ToppedCarrotsStandards.pdf $>$.

USDA NASS. 2020. NASS-Quick Stats. 28 Jan. 2021. <https://quickstats.nass.usda.gov/>.

Warren, J. and R. Taylor. 2014. Managing soil compaction. Okla. St. Univ. Ext. Fact Sheet PSS-2244. < <ttp://pods.dasnr.okstate.edu/docu share/dsweb/Services/Version-15659>.

White, J.M. 1992. Carrot yield when grown under three soil water concentrations. HortScience 27(2): 105-106, doi: 10.21273/HORTSCI.27.2.105. 